\title{
Positive Chronotropic and Inotropic Effects of Higenamine and Its Enhancing Action on the Aconitine-Induced Tachyarrhythmia in Isolated Murine Atria
}

\author{
Ikuko Kimura, Mitsuhiro Makino, Yusaku Takamura, Md. Amirul Islam and Masayasu Kimura \\ Department of Chemical Pharmacology, Faculty of Pharmaceutical Sciences. Toyama Medical and Pharmaceutical University, \\ 2630 Sugitani, Toyama 930-01, Japan
}

Received December 22, 1993 Accepted June 16, 1994

\begin{abstract}
Aconitine and higenamine are the components of aconite root. We investigated the cardiac effects of these compounds on murine right and left atria and the interaction of higenamine with aconitine on the rate of spontaneously beating right atria. Higenamine increased the rate $\left(\mathrm{EC}_{50}=38 \mathrm{nM}\right)$ and the force of contraction $\left(\mathrm{EC}_{50}=97 \mathrm{nM}\right)$, the maximal responses being comparable with those of isoproterenol. The positive chronotropic effect of higenamine was antagonized by propranolol $(30-300 \mathrm{nM})$ and practolol $(10$ $\mathrm{nM}-3 \mu \mathrm{M})$, but not by butoxamine $(1 \mu \mathrm{M})$, indicating that it was a $\beta_{1}$-adrenoceptor-mediated action. The positive chronotropic effect of higenamine was not changed by pretreatment with reserpine $(4 \mathrm{mg} / \mathrm{kg}$, i.p., $4 \mathrm{hr})$. Aconitine $(0.16-0.25 \mu \mathrm{M})$ induced tachyarrhythmia in right atria was attenuated by quinidine $(1 \mu \mathrm{M})$, atropine $(8.6 \mu \mathrm{M})$ and AF-DX $116(8.6 \mu \mathrm{M})$, suggesting that aconitine activates sodium channels and muscarinic receptors. Higenamine $(2.5 \mathrm{nM})$ and dobutamine $(1 \mathrm{nM})$ did not cause chronotropic effects by themselves, but enhanced the aconitine-induced tachyarrhythmia. These results indicate that higenamine is a $\beta_{1}$-adrenoceptor full agonist in murine atria and that the aconitine-induced tachyarrhythmia is augmented by the $\beta_{1}$-adrenergic action of higenamine.
\end{abstract}

Keywords: Tachyarrhythmia (aconitine-induced), Higenamine, Chronotropic effect, Inotropic effect, Murine atria

Aconite, a Sino-Japanese medicine, possesses a wide range of pharmacological actions (1). Aconitine, a main active component of aconite (1-4), induces cardiac arrhythmia $(5,6)$ and has been used as an animal model of arrhythmia (7). The arrhythmogenic effect of aconitine results from direct activation of $\mathrm{Na}^{+}$channels $(8,9)$. A cardiotonic compound, higenamine $[( \pm)$-demethylcoclaurine], was identified from a non-alkaloid fraction of aconite (10). Higenamine elicits a positive inotropic effect by activation of $\beta$-adrenoceptors and subsequent increase in $\mathrm{Ca}^{2+}$ influx $(11,12)$. We found in mice that aconitine $(30 \mu \mathrm{g} / \mathrm{kg}$, i.p.) produces a decrease in heart rate to $50 \%$ of the basal level within 20 min after administration, and this effect of aconitine is mediated by activation of muscarinic receptors in the central nervous system (13). Interestingly, higenamine $(10 \mu \mathrm{g} / \mathrm{kg}$, i.p.) inhibited the bradycardia induced by aconitine in mice in vivo (13). The present experiments were carried out first to analyze the pharmacological characteristics of the cardiac effects of higenamine and aconitine and second, to further eluci- date the mechanism of interaction between aconitine and higenamine in isolated murine atria.

\section{MATERIALS AND METHODS}

Animals

Male ddY mice weighing $32-42 \mathrm{~g}$ (7- to 9-week-old) were used.

\section{Preparation of isolated murine atria}

Mice were sacrificed by decapitation and exsanguination. The thorax was opened, and the heart was rapidly removed and placed in Krebs-Henseleit solution. The solution was composed of $118.4 \mathrm{mM} \mathrm{NaCl}, 4.69 \mathrm{mM} \mathrm{KCl}$, $2.0 \mathrm{mM} \mathrm{CaCl}_{2}, 1.16 \mathrm{mM} \mathrm{MgCl}_{2}, 12.4 \mathrm{mM} \mathrm{NaHCO}_{3}$ and $5.0 \mathrm{mM}$ glucose and gassed with $95 \% \mathrm{O}_{2}-5 \% \mathrm{CO}_{2}$ at $30^{\circ} \mathrm{C}$. Right and left atria were separated from the ventricle and other tissues, respectively. The atrial preparations were connected to an isometric transducer (model UL2GR; Minebea, Nagano) by a silk thread, and they were 
suspended under a resting tension of $1 \mathrm{mN}$ in an organ bath containing $2.5 \mathrm{ml}$ Krebs-Henseleit solution.

\section{Experimental procedures}

The right atrial preparations were equilibrated until the rate of contraction reaches a stable level of approximately $4 \mathrm{~Hz}$. The left atria were electrically driven by means of field stimulation (3-msec pulse duration, 1.5-fold threshold-voltage at $4 \mathrm{~Hz}$ ) via platinum bipolar electrodes and equilibrated for $1 \mathrm{hr}$. The stimulus pulse was generated by an electronic stimulator (SEN-3201; Nihon Kohden, Tokyo) and applied through an isolator (45-201J, Nihon Kohden). The receptor antagonists and ion channel inhibitors were allowed to act for $5 \mathrm{~min}$ before the application of the test drugs. The concentration-response curves of aconitine, practolol, isoproterenol and $( \pm)$ higenamine were determined by cumulative administration. The concentration of the drugs was increased stepwise every $2 \mathrm{~min}$. The rate and the force of contraction were recorded on a pen-writing oscillograph (type 5108 , Nihon Kohden). The rate of contraction was calculated by measuring the time required for 20 beats on the actual recordings. The rate of contraction was calculated in a similar manner after the administration of aconitine in the concentration range of $0.16-0.25 \mu \mathrm{M}$. Aconitine at these concentrations did not induce atrial flutter and fibrillation.

\section{Drugs used}

The following drugs were used: aconitine, lidocaine, butoxamine $\mathrm{HCl}$ (Sigma Chemical, St. Louis, MO, USA); atropine sulfate (Merck, Darmstadt, Germany); scopolamine $\mathrm{HBr}$, quinidine (Wako, Osaka); AF-DX 116 (Boehringer Ingelheim, Ingelheim, Germany); verapamil $\mathrm{HCl}$ (Knoll, Ludwigshafen, Germany); diltiazem (Tanabe, Tokyo); ( \pm )-isoproterenol (Kaken, Tokyo); propranolol $\mathbf{H C l}$, reserpine (Nacalai Tesque, Kyoto); practolol (Takeda, Tokyo); dobutamine (Shionogi, Osaka); ( \pm )-higenamine $\mathrm{HBr}$ (provided by Profs. T. Kikuchi, Research Institute for Wakan-Yaku, and T. Momose, Department of Pharmaceutical Chemistry, Toyama Medical and Pharmaceutical University).

\section{Statistical analyses}

Significant differences between mean values for the control and after administration of drugs were evaluated by means of analysis of variance (ANOVA) and the multiple range test of Newman-Kewls. The difference was considered to be significant when the $P$ value was smaller than 0.05 .

The Hill coefficient and $\mathrm{pA}_{2}$ values were estimated by the method of Arunlakshana and Schild (14).

\section{RESULTS}

\section{Chronotropic effect of higenamine on right atria}

Higenamine ( $3 \mathrm{nM}-3, \mu \mathrm{M})$ (Fig. 1) and isoproterenol $(0.1-100 \mathrm{nM})$ induced a positive chronotropic effect on right atria in a concentration-dependent manner. The response reached a steady level within $2 \mathrm{~min}$. The maximal responses of $8.24 \pm 0.11(n=4)$ and $8.07 \pm 0.1 \mathrm{~Hz}$ $(\mathrm{n}=4)$ were achieved by isoproterenol $(0.1 \mu \mathrm{M})$ and higenamine $(3 \mu \mathrm{M})$, respectively. The intrinsic activity of higenamine $(0.98)$ was comparable to that of isoproterenol (1.0). The $\mathrm{EC}_{50}$ values of isoproterenol and higenamine were $1.98 \mathrm{nM}$ ( $95 \%$ confidence limit: $1.82-2.15$ $\mathrm{nM})$ and $37.9 \mathrm{nM}(32.6-44.5 \mathrm{nM})$, respectively, indicating that higenamine is approximately 20 times less potent than isoproterenol.

Propranolol $(0.03-0.3 \mu \mathrm{M})$ shifted to the right the concentration-response curves of higenamine (Fig. 1) and isoproterenol in parallel. Schild plots of the antagonistic action of propranolol on the positive chronotropic effect of higenamine and isoproterenol demonstrated that Hill coefficients (1.14 and 1.16) and $\mathrm{pA}_{2}$ values (7.94 and 8.06) for the antagonistic action of propranolol against the positive chronotropic effects of higenamine and isoproterenol were comparable, respectively.

Higenamine did not show tachyphylaxis. The positive chronotropic effect of higenamine was not inhibited by reserpine $(4 \mathrm{mg} / \mathrm{kg}$, i.p., $4 \mathrm{hr}$ )-pretreatment (data not shown). The pretreatment is enough to deplete catecholamines in the heart of rat $(15,16)$.

Inhibition by $\beta_{1}$-adrenergic blocking agents of the positive chronotropic effect of higenamine

Higenamine at $38 \mathrm{nM}$ and isoproterenol at $2 \mathrm{nM}$ induced a positive chronotropic action equivalent to $50 \%$ of the maximal response. A $\beta_{1}$-adrenergic blocking agent, practolol $(10 \mathrm{nM}-3 \mu \mathrm{M})$, inhibited the positive chronotropic effects of $38 \mathrm{nM}$ higenamine and $2 \mathrm{nM}$ isoproterenol in a concentration-dependent manner in isolated right atria (Fig. 2). In contrast, butoxamine $(1 \mu \mathrm{M}), a \beta_{2}$-adrenergic blocking agent, did not affect the chronotropic effects of higenamine and isoproterenol (data not shown). These results indicate that the positive chronotropic effects of higenamine and isoproterenol are mediated by $\beta_{1}$-adrenergic receptors.

\section{Positive inotropic effects of higenamine}

Higenamine (12.5-800 nM) (Fig. 1, upper panel and Fig. 3) and isoproterenol (0.625-40 nM) (Fig. 3) caused a positive inotropic effect in a concentration-dependent manner in isolated left atria. The $\mathrm{EC}_{50}$ values of isoproterenol and higenamine were $4.89 \mathrm{nM}(95 \%$ confidence limit: $4.54-5.28 \mathrm{nM})$ and $97.0 \mathrm{nM}(81.5-115.2 \mathrm{nM})$, 

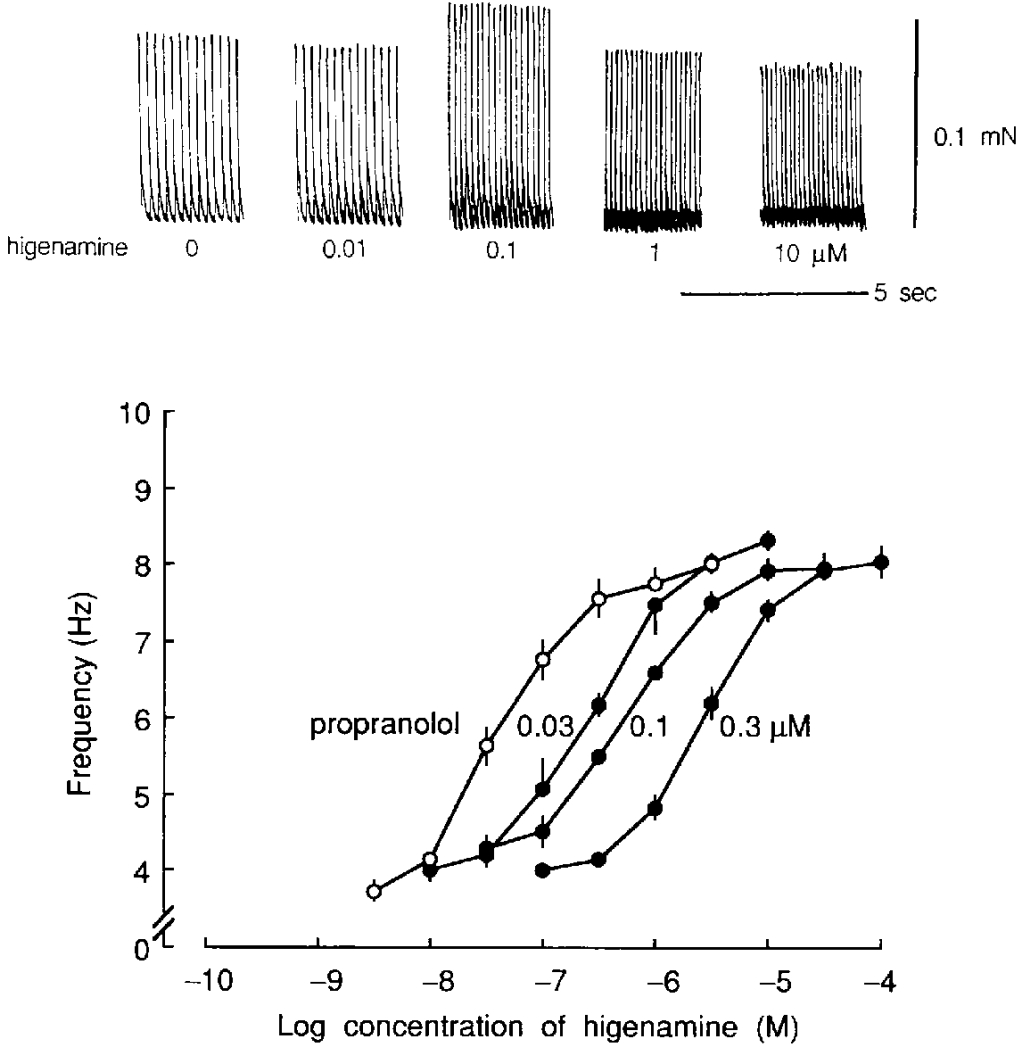

Fig. 1. Typical data (upper panel) and concentration-response curves for the positive chronotropic effects of higenamine (lower panel) in the absence (open circles) or presence (closed circles) of propranolol $(0.03,0.1,0.3 \mu \mathrm{M})$ in murine right atria. Propranolol was allowed to act for $5 \mathrm{~min}$ before the addition of higenamine and present throughout the experiments. Each value represents a mean \pm S.E.M. $(n=4)$.

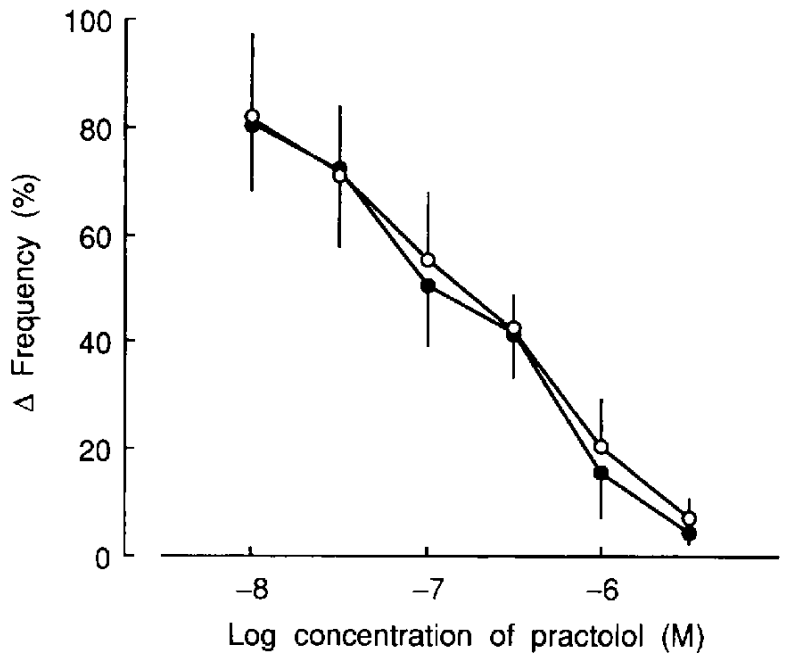

Fig. 2. Inhibitory effects of practolol $(10 \mathrm{nM}-3 / \mathrm{M})$ on the positive chronotropic effect of higenamine (closed circles: $38 \mathrm{nM}$ ) and isoproterenol (open circles: $2 \mathrm{nM}$ ) in murine right atria. Higenamine and isoproterenol were administrated 5 min before the first addition of practolol. Practolol was added in a cumulative manner at 2 min intervals where the response attained a steady level. The responses were expressed as a percentage relative to the effect of higenamine alone $(5.40 \mathrm{~Hz})$ or isoproterenol alone $(5.92 \mathrm{~Hz})$. Each value represents a mean \pm S.E.M. $(n=4)$.

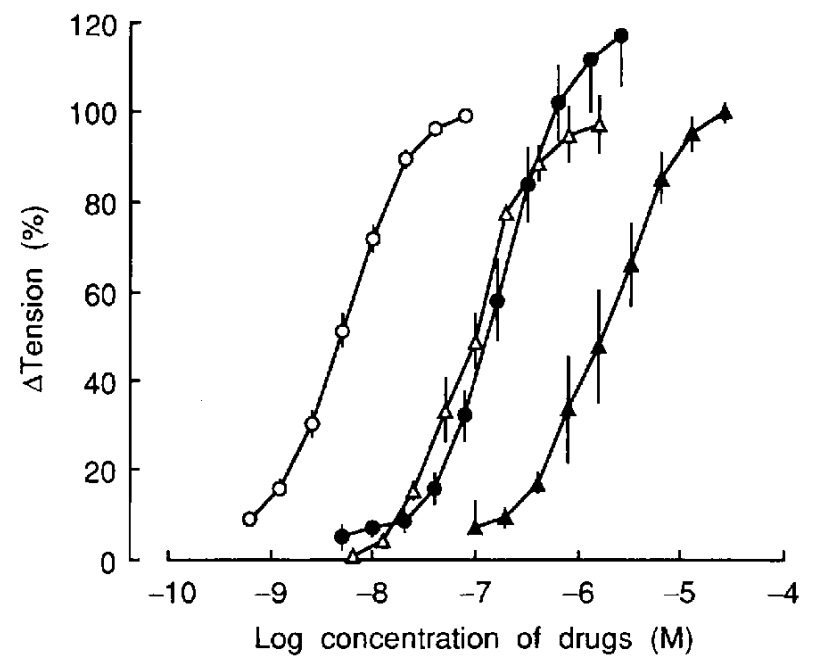

Fig. 3. Positive inotropic effects of higenamine (triangles) and isoproterenol (circles) in the absence (open symbols) or presence (closed symbols) of propranolol $(0,1 / t \mathbf{M})$ in murine left atria (electrically driven by at $4 \mathrm{~Hz}$ ). Propranolol was allowed to act for $5 \mathrm{~min}$ before the addition of the test agent and present throughout the experiments. Each value represents a mean \pm S.E.M. $(n=4-18)$. 

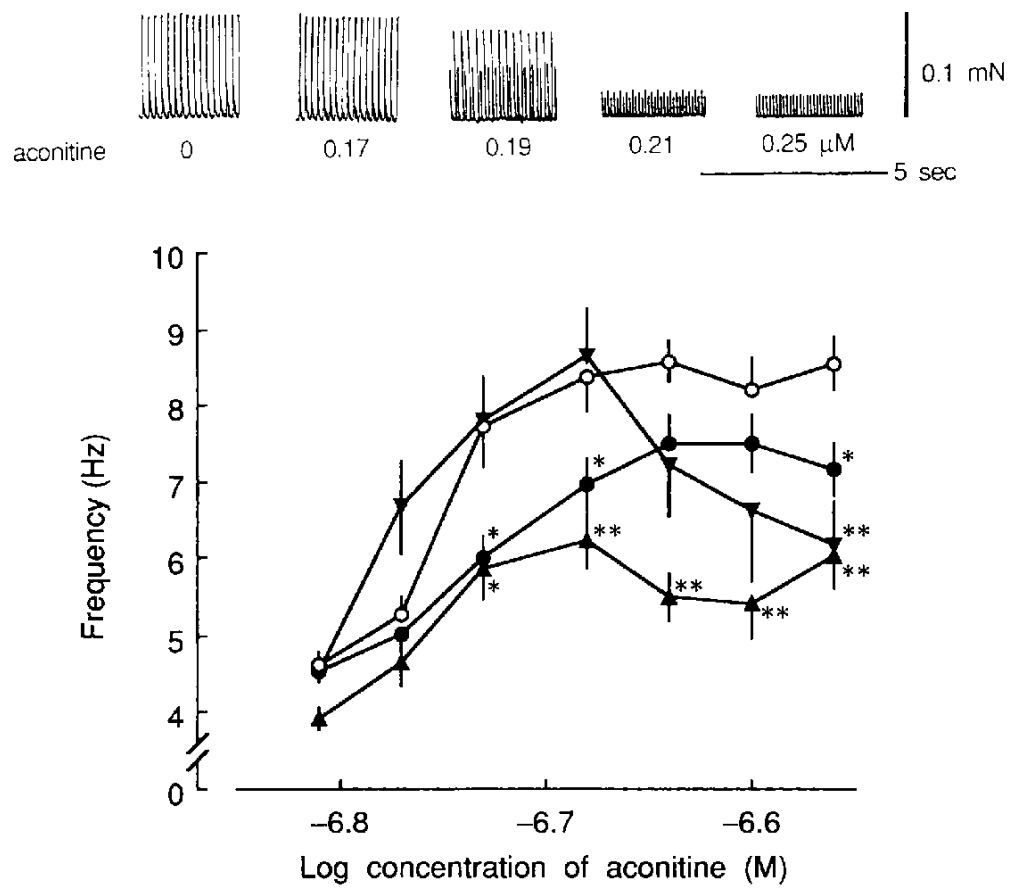

Fig. 4. Typical data (upper panel) and inhibitory effects (lower panel) of atropine (8.6 $\mu \mathrm{M}$, closed circles), AF-DX 116 (8.6 $\mu \mathrm{M}$, upward triangles) and scopolamine ( $8.6 \mu \mathrm{M}$, downward triangles) on the aconitine (open circles)-induced tachyarrhythmia in murine right atria. Each value represents a mean \pm S.E.M. $(n=6-10) .{ }^{*} \mathrm{P}<0.05,{ }^{* *} \mathrm{P}<0.01$ vs. the control by means of ANOVA and the multiple range test of Newman-Kewls.

respectively, indicating that higenamine is approximately 20 times less potent than isoproterenol. The intrinsic activity of higenamine (0.94) was comparable to that of isoproterenol (1.0).

\section{Positive chronotropic effects of aconitine}

Aconitine $(0.17-0.25 \mu \mathrm{M})$ induced a positive chronotropic effect that was followed by bigeminy in the right atria (Fig. 4, upper panel).

Quinidine, a sodium channel blocking and anti-arrhythmic agent (class Ia), significantly suppressed the aconitine-induced tachycardia and bigeminy at a concentration of $1 \mu \mathrm{M}$, a dose that did not affect the basal rate by itself. Lidocaine $(3 \mu \mathrm{M})$, verapamil $(10 \mathrm{nM})$ and diltiazem $(10 \mathrm{nM})$ did not affect the aconitine-induced tachyarrhythmia (data not shown).

Inhibition by muscarinic receptor antagonists of aconitine-induced tachyarrhythmia

The muscarinic antagonist atropine $(8.6 \mu \mathrm{M})$ and the $\mathrm{M}_{2}$-selective antagonist AF-DX $116(8.6 \mu \mathrm{M})$ suppressed significantly the aconitine-induced tachyarrhythmia. Scopolamine $(8.6 \mu \mathrm{M})$ suppressed the aconitine-induced tachyarrhythmia to a lesser extent (Fig. 4, lower).
Enhancement of the aconitine-induced tachyarrhythmia by higenamine and dobutamine

Higenamine ( $2.5 \mathrm{nM})$ did not affect the rate of contraction, but enhanced the aconitine-induced tachyarrhyth-

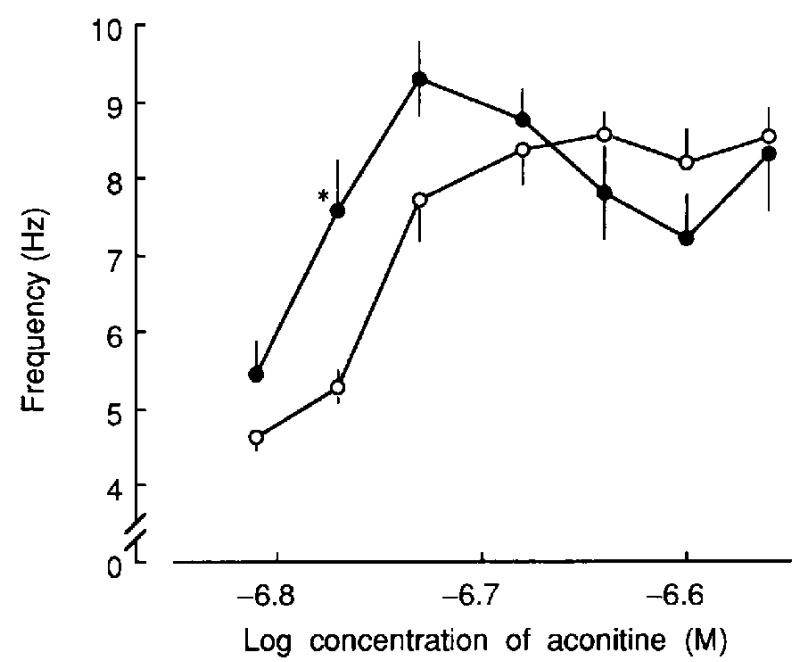

Fig. 5. Enhancement by higenamine ( $2.5 \mathrm{nM}$, closed circles) on the aconitine (open circles)-induced tachyarrhythmia in murine right atria. Each value represents a mean \pm S.E.M. $(n=6-10) .{ }^{*} \mathrm{P}<0.05$ vs. the control by means of ANOVA and the multiple range test of Newman-Kewls. 


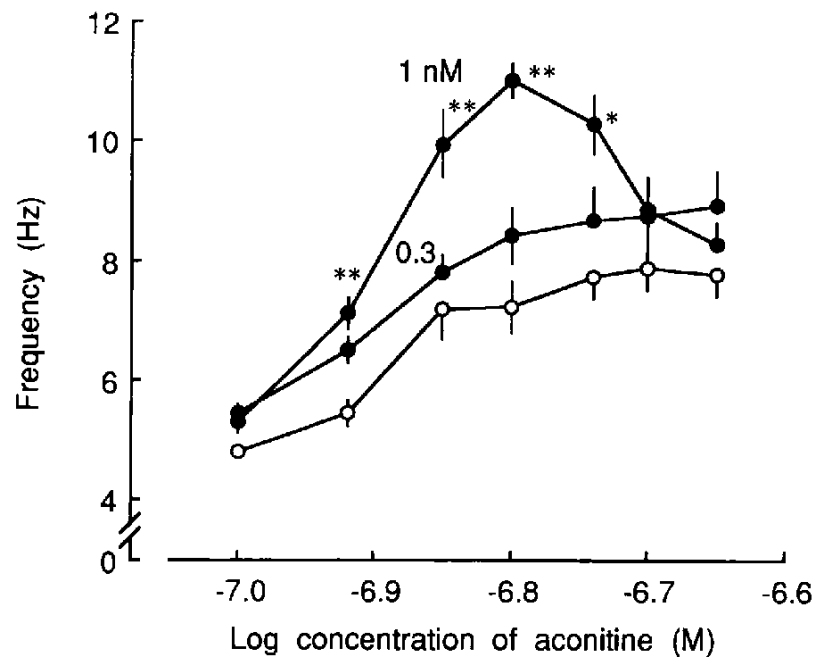

Fig. 6. Enhancement by dobutamine ( 0.3 and $1 \mathrm{nM}$, closed circles) on the aconitine (open circles)-induced tachyarrhythmia in murine right atria. Each value represents a mean \pm S.E.M. $(n=6-10)$. ${ }^{*} \mathrm{P}<0.05,{ }^{* *} \mathrm{P}<0.01$ vs. the control by means of ANOVA and the multiple range test of Newman-Kewls.

mia in isolated right atria (Fig. 5).

Dobutamine, a selective $\beta_{1}$-adrenoceptor agonist, at 0.3 and $1 \mathrm{nM}$ did not elicit any chronotropic effect by itself, but likewise enhanced the aconitine-induced tachyarrhythmia as shown in Fig. 6.

\section{DISCUSSION}

Processed aconite is frequently prescribed as a traditional Chinese medicine. The processed preparation of aconite contains aconitine, mesaconitine, higenamine, coryneine and many other principles. We have found by in vivo experiments in mice that aconitine produces bradycardia in association with bigeminy and that higenamine inhibited the aconitine-induced bradycardia (13). While the effect of aconitine seems to be produced through a central muscarinic mechanism, the mechanism for higenamine-induced is unknown. Because aconitine also produces tachyarrhythmia in isolated atria (17), the present study was performed to elucidate the mechanism of interaction between aconitine and higenamine in isolated murine atria.

In murine atria, higenamine elicited a concentrationdependent positive chronotropic effect. The positive chronotropic effect of higenamine was inhibited by propranolol and the $\hat{\beta}_{1}$-antagonist practolol, but not by the $\beta_{2}$-antagonist butoxamine, indicating that higenamine induces a positive chronotropic effect via activation of cardiac $\beta_{1}$-adrenoceptors. The chronotropic effect of higenamine is not due to the release of catecholamines, because the pretreatment with reserpine did not inhibit the positive chronotropic effect of higenamine.

Higenamine, a cyclic catecholamine, has been shown to elicit a chronotropic effect on cultured rat heart cells. The effect of higenamine is antagonized by pindolol (18). Higenamine increases the plasma cyclic AMP content in mice. The affinity of isoproterenol for the $\beta$-adrenoceptor in turkey erythrocyte membrane is similar to that of higenamine, whereas the intrinsic activity of higenamine on cyclic AMP generation is 0.29 of that for isoproterenol (19). $\hat{\beta}$-Adrenergic stimulation increases $\mathrm{Ca}^{2+}$ influx in myocardial cells by the pathway of cyclic AMP and cyclic AMP-dependent protein kinase (20). Kimura et al. (12) have reported that higenamine shifts the concentrationinotropic response curve of $\mathrm{Ca}^{2+}$ in parallel to the left in guinea pig papillary muscle. The positive inotropic action of higenamine is likely due to stimulation of cardiac adrenoceptors (11).

Aconitine is known as an activator of the voltage-dependent sodium channel and a partial ligand to the sodium channel $(21,22)$. Aconitine produces tachyarrhythmia in isolated atria. The concentration range of aconitine for inducing tachyarrhythmia was very narrow $(0.16-0.25$ $\mu \mathrm{M})$. At concentrations higher than $0.25 \mu \mathrm{M}$, aconitine suppressed the rate of beating in murine atria. Quinidine, but not lidocaine, suppressed the aconitine-induced tachyarrhythmia. Though both antiarrhythmic drugs belong to the family of $\mathrm{Na}$ channel blocking agents, the action potential duration is prolonged by quinidine and shortened by lidocaine. Therefore the suppression induced by quinidine may partially be due to the $\mathrm{Na}$ channel inhibition in association with prolongation of action potential duration.

Aconitine increases ACh content in isolated canine right atria (23). Aconitine may stimulate $\mathrm{ACh}$ release from presynaptic nerves by activation of sodium channels. Cholinergic agonists and vagal stimulation potentiate the inducibility of atrial fibrillation and tachyarrhythmias in isolated canine right atria (24), suggesting that ACh released by aconitine may contribute to the arrhythmogenic action of aconitine, in addition to sodium channel activation. In murine atria, muscarinic antagonists, atropine, scopolamine, and AF-DX 116 (a selective $M_{2}$-receptor antagonist), suppressed the tachyarrhythmia induced by aconitine. Quinidine may likewise attenuate the release of $\mathrm{ACh}$ by inhibition of the sodium channel in presynaptic nerve terminals. In addition, quinidine has an anti-muscarinic effect at the receptor binding site $(25,26)$. The quinidine-induced suppression of the aconitine-induced tachyarrhythmia may involve the diverse effects of this compound on muscarinic signal transduction. Verapamil and diltiazem had no effect on aconitine-induced tachyarrhythmia, indicating a less significant contribution of the activation of L-type calcium 
channels.

Higenamine enhances the aconitine-induced tachyarrhythmia in isolated murine atria, while it inhibited the aconitine-induced bradycardia in vivo (13). The aconitine-induced tachyarrhythmia was likewise enhanced by dobutamine, a $\hat{\beta}_{1}$-agonist, indicating that the $\hat{\beta}_{1}$ adrenoceptor activation plays a crucial role, because higenamine stimulates $\beta_{1}$-adrenoceptors in murine atria (Figs. 1 and 2).

In conclusion, activation of sodium channels and muscarinic receptors by aconitine may play a crucial role in the aconitine-induced tachyarrhythmia in murine atria. Activation of $\beta_{1}$-adrenoceptors by higenamine as well as dobutamine augment the aconitine-induced tachyarrhythmia.

\section{Acknowledgments}

We thank Dr. T. Kikuchi, Research Institute for Wakan-Yaku, and Dr. T. Momose, Department of Pharmaceutical Chemistry, Toyama Medical and Pharmaceutical University, for providing higenamine; and we thank Boehringer Ingelheim, Japan for donating AF-DX 116

\section{REFERENCES}

1 Hikino H, Sato H, Yamada C, Konno C, Ohizumi Y and Endo K: Pharmacological actions of Aconitum roots. Yakugaku Zasshi 99, 252-263 (1979) (Abstr in English)

2 Hikino $\mathrm{H}$, Yamada $\mathrm{C}$, Nakamura $\mathrm{K}$, Sato $\mathrm{H}$, Ohizumi $\mathrm{Y}$ and Endo K: Change of alkaloid composition and acute toxicity of Aconitum roots during processing. Yakugaku Zasshi 97, 359-366 (1977) (Abstr in English)

3 Sato $\mathbf{H}$, Yamada C, Konno C, Ohizumi Y, Endo $\mathrm{K}$ and Hikino $\mathrm{H}$ : Pharmacological action of aconitine alkaloids. Tohoku J Exp Med 128, 175-187 (1979)

4 Kimura M, Muroi M, Kimura I, Sakai $\mathrm{S}$ and Kitagawa I: Hypaconitine, the dominant constituent responsible for the neuromuscular blocking action of the Japanese-Sino medicine "bushi" (aconite root). Jpn J Pharmacol 48, 290-293 (1988)

5 Scherf D: Studies on auricular tachycardia caused by aconitine administration. Proc Soc Exp Biol Med 64, 233-239 (1947)

6 Hollander PB and Webb JL: Procedure to initiate a sustained aconitine-induced electrical arrhythmia in isolated intrinsicallybeating paired atria and left atrium of rat. Life Sci 6, 249-260 (1967)

7 Sinha JN, Shamsi MA, Kohli RP and Bhargava KP: Centrogenic cardiac arrhythmia induced by aconitine: A new "model" for screening of anti-arrhythmic drugs. Jpn J Pharmacol 21 , $699-706$ (1971)

8 Sawanobori $\mathrm{T}$, Hirano $\mathrm{Y}$ and Hiraoka M: Aconitine-induced delayed afterdepolarization in frog atrium and guinea pig papillary muscles in the presence of low concentrations of $\mathrm{Ca}^{2+} . \mathrm{Jpn}$ J Physiol 37, 59-79 (1987)

9 Honerjäger $\mathrm{P}$ and Meissner A: The positive inotropic effect of aconitine. Naunyn Schmiedebergs Arch Pharmacol 322, 49-58 (1983)
10 Kosuge $\mathrm{T}$ and Yokota $\mathrm{M}$ : Studies on cardiac principle of aconite root. Chem Pharm Bull (Tokyo) 24, 176-178 (1976)

11 Park CW, Chang $\mathrm{KC}$ and Lim JK: Effects of higenamine on isolated heart adrenoceptor of rabbit. Arch Int Pharmacodyn Ther 267, 279-288 (1984)

12 Kimura I, Chui LH, Fujitani K, Kikuchi T and Kimura M: Inotropic effects of $( \pm)$-higenamine and its chemically related components, $(+)$ - $R$-coclaurine and $(+)-S$-reticuline, contained in the traditional Sino-Japanese medicines "Bushi" and "Shin-i" in isolated guinea pig papillary muscle. Jpn J Pharmacol 50, $75-78$ (1989)

13 Kimura I, Makino $\mathbf{M}$, Matsui $\mathrm{T}$, Takada $\mathbf{M}$ and Kimura $\mathbf{M}$ : Aconitine-induced bradycardia, centrally acting muscarinic is inhibited peripherally by higenamine in conscious mice. Phytother Res 8, 129-134 (1994)

14 Arunlakshana $\mathrm{O}$ and Schild $\mathrm{HO}$ : Some quantitative uses of drug antagonists. Br J Pharmacol 14, 48-58 (1959)

15 Norberg K-A: Drug induced changes in monoamine levels in the sympathetic adrenergic ganglion cells and terminals. Acta Physiol Scand 65, 221-234 (1965)

16 Sjöstrand NO and Swedin G: Effects of reserpine on the noradrenaline content of the vas deferens and the seminal vesicle compared with the submaxillary gland and the heart of rat. Acta Physiol Scand 72, 370-377 (1968)

17 Sharma PL: Mechanism of atrial flutter and fibrillation induced by aconitine in dogs, with observation on role of cholinergic factors. Br J Pharmacol 21, 368-377 (1963)

18 Han H-W, Wang J-Z and Sun F-L: Effect of $d$-demethylcoclaurine on cultured rat heart cells. Acta Pharmacol Sinica 2, $111-114$ (1981)

19 Feng Y-P, Jia H-J, Zhang L-Y and Zeng G-Y: Effect of $d l$ demethylcoclaurine on $\beta$-adrenergic receptors and adenylate cyclase in turkey erythrocyte membrane. Acta Pharm Sinica 17, $641-646$ (1982)

20 Sperelakis $\mathrm{N}$ and Wahler GM: Regulation of $\mathrm{Ca}^{2}$ influx in myocardial cells by beta adrenergic receptors, cyclic nucleotides, and phosphorylation. Mol Cell Biochem 82, 19-28 (1988)

21 Catterall WA: Neurotoxins that act on voltage-sensitive sodium channels in excitable membranes. Annu Rev Pharmacol Toxicol 20, $15-43$ (1980)

22 Catterall WA: The molecular basis of neural excitability. Science 223, 653-661 (1984)

23 Madan BR, Khanna NK and Soni RK: Effect of some arrhythmogenic agents upon acetylcholine content of the rabbit atria. I Pharm Pharmacol 22, 62I-622 (1970)

24 Schuessler RB, Grayson TM, Bromberg BI, Cox JL and Boineau JP: Cholinergically mediated tachyarrhythmias induced by a single extrastimulus in the isolated canine right atrium. Circ Res 71, 1254-1267 (1992)

25 Nakajima T, Kurachi Y, Ito H, Takikawa R and Sugimoto T: Anti-cholinergic effect of quinidine, disopyramide and procainamide in isolated atrial myocytes: Mediation by different molecular mechanisms. Circ Res 64, 297-303 (1989)

26 Nishimura M, Huan R-M, Habuchi Y, Honma N and Watanabe $\mathrm{Y}$ : Anticholinergic action of quinidine sulfate in rabbit atrioventricular node. Naunyn Schmiedebergs Arch Pharmacol 341, $517-524(1990)$ 